\title{
The Regulation Paradox of Initial Coin Offerings: A Case Study Approach
}

\author{
Alfred Ruoxi Zhang, Anujan Raveenthiran, Justin Mukai, Ramisha Naeem, Arvin Dhuna, \\ Zoha Parveen and Henry Kim*
}

Schulich School of Business, York University, Toronto, ON, Canada

Compared to Initial Public Offerings (IPOs) and conventional loans, Initial Coin Offerings (ICOs) are sales of promises of cryptocurrency appreciation. However, regulatory uncertainties continue to prohibit successful widespread adoption. This paper examines ICOs with varying levels of success, including Mastercoin (now Omni) and Kin, as well as fraudulent ICOs, like REcoin and OneCoin. The discussion of the ICO market focuses on the "regulation paradox," examining some of the inherent contradictions between

OPEN ACCESS

Edited by:

Diego Valiante

European Commission Headquarters,

Belgium

Reviewed by:

James Burnie,

Eversheds Sutherland (International) LLP, United Kingdom

Dang Du,

United States Blockchain \& Cryptocurrency Association,

United States

${ }^{*}$ Correspondence:

Henry Kim

hmkim@yorku.ca

Specialty section

This article was submitted to

Financial Blockchain,

a section of the journal

Frontiers in Blockchain

Received: 14 November 2018

Accepted: 13 March 2019

Published: 05 April 2019

Citation:

Zhang AR, Raveenthiran A, Mukai J,

Naeem $R$, Dhuna A, Parveen $Z$ and Kim H (2019) The Regulation Paradox of Initial Coin Offerings: A Case Study

Approach. Front. Blockchain 2:2. doi: 10.3389/fbloc.2019.00002 regulatory actions and values that differentiate ICO schemes from other investment instruments, and therefore questioning the capability of regulations to enhance investor protection mechanisms without undermining the fundamental value of cryptocurrencies and ICOs as a viable funding structure.

Keywords: blockchain, cryptocurrency, ICO, investment, policy, regulation

\section{INTRODUCTION}

Following the initial emergence of cryptocurrencies, supported by blockchain technology combining "peer-to-peer file sharing with public key cryptography" (Swan, 2015, p. vii), some businesses have begun to create their own cryptocurrencies as an alternative financing mechanism to raise capital. Many of these businesses have proposed projects in which specific cryptocurrencies, supported by specific blockchains, play an integral role in a digital service ecosystem, or are supported by various possible methods of exchange between users. Perceived benefits of certain cryptocurrencies, including security and anonymity, have attracted some investors to participate in ICOs. An ICO allows businesses to fund their project ventures through pre-sales, or crowdsales, of these digital currencies to investors who seek to profit. These currencies appreciate in value due to changes in their supply and demand after the businesses start operations. One of the most successful cryptocurrencies in the world, perceived by many observers to be the most successful cryptocurrency, is Bitcoin, as shown by its ranking in price, volume, and market capitalization (CoinMarketCap, 2017). In popular culture, the cryptocurrency industry has been regarded by many as the "Bitcoin industry," while other cryptocurrencies are regarded as Bitcoin alternatives, or "altcoins" (Wilmoth, 2014). For the purpose of this paper, terms including cryptocurrency, altcoin, and token will be used interchangeably.

In comparison to other financing methods, ICOs offer both significant advantages and certain disadvantages for both firms and investors, concerning risk and reward potential. IPOs dilute existing shareholder ownership and may offer dividends to investors, while debt financing entails guaranteed principal repayment to investors. In contrast, ICOs can be perceived as sales of the expectations outlined in white papers issued by firm founders. The issuer believes that the 
cryptocurrency purchased by investors will become more valuable as demand increases due to more consumers seeking to use it in online activities and transactions. ICOs allow companies to "bypass the rigorous and regulated capital-raising process required by venture capitalists or banks," and mitigate some risks since "if the money raised does not meet the minimum funds required by the firm, the money is returned to the backers" (Investopedia., 2018). However, these benefits, including convenience and minimal obligatory financial risks enjoyed by companies, do not come without the added risks and disadvantages to investors. While government instruments like U.S BitLicenses exist, their contexts have been "extremely broad, wide-reaching, and extraterritorial” (Swan, 2015, p. 87). Hence, stringent and well-understood regulations have yet to be effectively implemented in this industry at an optimal level, and both project founders, as well as investors, are acting with a high degree of uncertainty concerning legal structures. The high risks are borne by the market participants themselves. Because of these problems, while some successful ICOs do exist, existing regulatory gaps have, in part, enabled fraudulent or criminal activities that resulted in investor losses (Redman, 2016; Morris, 2017). From a global perspective, regulatory responses have varied drastically. Some governments attempt to target individual cases of failure by approaching them as either traditional financial security issuances or criminal organizations with malicious intent. Moreover, other governments from countries such as China have imposed outright bans on ICOs, in fear of both chaotic market conditions and the formation of a decentralized economy which escapes government oversight (Reuters, 2017).

In this paper, a series of successful ICOs will be discussed, including Mastercoin and Kin. Furthermore, REcoin and OneCoin are controversial examples that will be discussed as they are perceived as fraudulent (Redman, 2016; Morris, 2017). The focus of this discussion will be understanding the benefits brought by cryptocurrencies and ICOs to businesses and investors, as well as the flaws of the current immature market mechanisms without regulations. Operating under the assumption that in the near future, the expanded use of cryptocurrencies would inevitably lead to a scenario in which improved regulations would have to be implemented, this paper argues that a paradox exists as the values of ICOs fundamentally conflict with contemporary regulatory methods. This paper also further discusses certain possible directions that future regulations could take, and whether or not these approaches could benefit the market participants without undermining the emerging economic and technological advancements.

\section{BLOCKCHAIN, CRYPTOCURRENCY, AND ICO}

In order to get a better understanding of ICOs, it is important that relevant fundamental concepts related to this topic, including blockchain and cryptocurrency, are understood in the context of further discussion. This section of the paper is dedicated to conveying a basic explanation of these terms, without delving into unnecessarily complex technical details.

\section{Blockchain}

Blockchain is a decentralized digital ledger that stores, connects and verifies information using blocks generated by many computers. While a typical "ledger" locates centrally either in a physical location or database, accessible by accountants in an organization, a decentralized digital ledger exists as many copies kept by all participants of a blockchain network. When a transaction is conducted, or a piece of information needs to be recorded, they are compiled with other entries of information into one encrypted "block," which is then sent via the Internet to be verified by all members of this network, or "miners." If the integrity of the block is confirmed, it is then broadcasted to the entire network, so that all participants can record it under their own copies of the ledger, as an addition to a series of previously mined blocks that reference their preceded ones like a "chain."

The most important trait of blockchain technology is data security. Data stored using blockchain technology is decentralized, meaning that although many computers are involved in processing and verifying one transaction, it is usually difficult for unauthorized parties to gain access to enough information to identify the entities who have participated in that transaction. Furthermore, as each block in a chain contains hashes, which are essentially references to the previous blocks, it would be nearly impossible to produce fraudulent entries on a blockchain network. Falsifying information on a blockchain network could virtually and literally require permissions from more than half of the participants in the system, or in technical terms $51 \%$ of the computing power. Meanwhile, as miners keep separate chains recording different blocks when some are in conflict and would only choose the longest chain in existence when building a new block, those who wish to commit fraud must maintain the depths of blocks with fraudulent information by sustaining the said majority computing power for longer than what is usually probable (BlockGeeks, 2016).

\section{Cryptocurrency}

Cryptocurrency, also known as tokens, is not actual currency issued by monetary agencies, rather it is a combination of virtual currency and a commodity as it has a fixed supply, controlled by algorithms and is a store of value. As introduced previously, since blockchain is essentially a distributed digital ledger, transactions recorded on the chain, with considerable block depths, would be as highly trusted by participants of this network as those recorded on the centralized ledgers of commercial banks, due to blockchain's nature of being secure. Therefore, just like depositing accounts held by banks, records on a blockchain showing debts held on other parties are trusted enough to become a store of value and a medium of exchange. Those exposed to these traits quickly act to define their own units of account, such as Bitcoin, fulfilling some of the common qualities of currencies, and thus "cryptocurrency" is derived.

It is to be emphasized here that, while legal currencies are reliable because they are backed by central banks, cryptocurrencies are regarded as reliable by users due to the security of their fundamental cryptographic designs. However, risks should always be cautiously perceived in relative terms, as while central banks could lose their ability to support a 
monetary system in face of force majeure, such as a war or other consequences of disastrous policies, cryptocurrencies are also prone to " $51 \%$ attacks," in which more than $50 \%$ of computing power is controlled by hackers to overwhelm a blockchain system. In the topic of social economics, one might also argue that, in comparison to many currencies suffering from fluctuations of ephemeral political reigns in the global south, cryptocurrencies that are not confined by boundaries of nations could be a more reliable alternative, able to benefit local economies.

In comparison to traditional currencies, unless pegged to some particular legal currencies, cryptocurrencies have independence from monetary policy influence and financial intermediary intervention. Cryptocurrencies also avoid a great portion of costs incurred by limited divisibility and commissions. However, it is not free from risks and market mechanisms borne by most currencies, thus, cryptocurrencies often tend to experience much greater fluctuations in value than typical currencies do, prompted by speculative investors and the uncertain nature of regulatory reforms which affect potential user growth (Conley, 2017). The value of cryptocurrency is determined by the mathematical computation of factors that are driven by demand and supply. Cryptocurrencies have a limited supply due to controlled circulation, which enables the eventual actualization of theoretical limits. As a result, cryptocurrency value is mostly driven by demand, which, similar to traditional currency exchange markets, is driven by confidence in its purchasing power, the valuation of prospective markets, speculation, and investor perspective, which all link directly to their operating platforms (Boggavaram, 2017).

First of all, confidence in the concept of cryptocurrencies themselves has been high, and they are accepted and adopted by many individuals as well as businesses because it gives users the confidence, in terms of extreme security of its underlining digital ledger. The technological advantages brought by blockchain fundamentally prevent transactions using cryptocurrencies from manipulation and duplication of digital assets in the broad sense. However, a significant factor that could affect such confidence comes from the stability of the projects backing the proliferation of each cryptocurrency. Second, the perspective of investors is another factor to consider. Individuals who invest in cryptocurrencies do so by evaluating how much control the cryptocurrency has over the market share and estimates the value of it based on the value of the asset that it replaces. Speculation is also a factor that drives the value of cryptocurrencies. Lastly, currency speculation adopted from financial and exchange markets is also rather common when many cryptocurrencies experience large swings in their prices, especially when the projects first launch, and such speculation would gradually drive to price convergence (Boggavaram, 2017).

Therefore, according to what has been introduced about blockchain and cryptocurrency, we can so far categorize blockchain projects into three different types. The first type includes blockchain application projects that do not involve the usage of cryptocurrencies. Some good examples belonging to this category are blockchain-based information systems, which have become quite a popular topic in the domain of medical care, academic research capitalization, and financial technology (Fintech). These projects often utilize blockchain technology to improve the efficiency of information exchanges and the integrity of private data or copyrighted materials, while not relying on cryptocurrencies to support their primary functions, thus immune to the swings of cryptocurrency market. The second type are projects in which cryptocurrencies are utilized primarily to facilitate the core functionalities of their corresponding platforms and do not overshadow the value of the technological applications. One fine example of this type is Ethereum, where the tokens are used to support Smart Contract operations, and such utility is what's truly piloting the value of Ethereum project. In contrast, a third type of blockchain project that does not focus on proposing value creation through applications of technology, but often more on the promises of token appreciation as an asset. Empirically they would experience the most significant fluctuations, as their demands are more driven by market trends and speculations, similar to financial securities.

\section{Investment}

As cryptocurrency enthusiast Yadav argues in his paper Yadav (2017), there are a few indicators that are usually considered by ICO investors. The first indicator is the policies of the governments toward cryptocurrencies. Historically, governments have taken different approaches to deal with both cryptocurrencies and issues involving them. For example, the Chinese government's strict ban of the entire cryptocurrency market caused huge price fluctuations in both Bitcoin and Ethereum. Another important investor consideration, which requires regulatory support, is the longevity of associated ventures, specifically for the past reputation of firms involved in ICOs. This is to avoid pump-and-dump schemes with unverifiable valuations or fraudulent activities. ICOs can be viewed by firms as a quick and effective method of raising capital without compliance pressures from significant regulatory oversight. As a result, many companies can raise more capital than they actually need in the short term for positive NPV projects. Companies or projects that have existed for long periods of time can be better evaluated in terms of the goals that these companies have, which should be a good indication of future strategy to guide individuals' investments. Looking into the crypto-community's perception of these projects can also be beneficial as the Blockchain system works in a communitylike environment, where the constant growth of communities suggests that people are interested and actively engaged in projects. Because of the tight-knit community size, developers themselves provide assessments on the risks involved with the technology. Last but most importantly, investors should look at the quality of information provided in ICO white papers, in which information regarding the intended use of funds and planned applications of the cryptocurrency is released. This could help draw a clear picture of the assets, plans and strategies of the projects. However, these investigations must be conducted by investors independently, as there are currently very few official structures in place to publish and verify information about ICO projects. 
As discussed in the last section, investments in pure blockchain application projects, projects that focus on building functional applications, as well as projects that are treated by investors more as securities, can be vastly different. Later sections focus on the ICOs of two later types and examines a few empirical cases to show both the benefits of a decent ICO project, as well as the harms that a fraudulent one can inflict on the investors. The paper continues to argue that, while investors could consider all the indicators introduced by Yadav, an underregulated market is still inappropriately risky to both investors and the aggregate economy, while an over regulated market on the other hand, could be detrimental to the future developments of this field. However, a middle ground might be very difficult to reach, as there are fundamental conflicts between the core values of cryptocurrencies and the contemporary regulatory methods, therefore resulting in the "regulation paradox."

\section{ICO: SUCCESSES AND ACHIEVEMENTS}

\section{Mastercoin}

As Shin introduced to us Shin (2017), Mastercoin, the first ICO, was launched in 2013 by J. R. Willett. Before his venture into the world of cryptocurrencies, Willett was a software engineer for a company specializing in manufacturing aircraft avionics. However, he began to get involved with cryptocurrencies after taking a substantial interest in Bitcoin. With a family to care for, Willett could not take any significant risks and directly invest in Bitcoin as it was difficult to ensure the security of his investment. Consequently, he decided to use some of his money to pay random people through Craigslist to run his own mining software. As he became more interested in Bitcoin and cryptocurrencies as a whole, Willett published a "white paper" that explained the benefits of issuing another cryptocurrency. After a year and a half of promoting his idea, Willett decided to take action and executed a cryptocurrency offering and was initially overwhelmed that a large number of individuals, with whom he had no previous acquaintance, were sending him money. Subsequently, other people learned of Willett's success and decided to conduct their own projects using this technology.

Despite trying to promote others to try his idea, Willett decided to execute his plan himself because he wanted to prove his idea was possible. Mastercoin was pitched as "The Second Bitcoin" and provided many benefits to Bitcoin including improving the stability of Bitcoin and adding value to the cryptocurrency network. Under the nickname, "dacoinminster," Willett published his white paper, which claimed that Mastercoin would "fix the two biggest barriers to widespread bitcoin adoption: instability and insecurity" (Guttmann, 2014, p. 407). His idea was to use the Bitcoin blockchain as a foundation for new currencies like Mastercoin. Because the new cryptocurrencies would be built upon the existing Bitcoin network, the underlying foundation of Bitcoin's blockchain would not change. It was using this assumption that Willett claimed that it was possible for anyone to create a new currency and build upon this foundation, without having the need for approval from other members of the cryptocurrency community. People took an interest in this idea, thus, the ICO was launched.
After the launch of Mastercoin, many people were skeptical about this business practice. Willett claimed that he received several threats informing him that he would be reported to the Securities and Exchange Commission (SEC) and eventually imprisoned. In general, public skepticism was fueled by the lack of regulation of ICOs. For the majority of the population, sending money to a stranger through the Internet was unconventional, to say the least. Because ICOs started as a "garage-band" project, there was no regulation for the transfer of money. In fact, If Willett had malicious intentions, he could have personally pocketed all of the donations he accumulated, instead of following through with his initiative. In his white paper, Willett even put a disclaimer in the document saying that it is extremely risky to invest in "experimental currency" (Guttmann, 2014, p. 408).

As virtual currencies started to become increasingly popular, the US Senate asked several agencies about their existing regulations and upcoming plans regarding cryptocurrencies. The Department of Homeland Security (DHS), Federal Reserve, and SEC were among the agencies that the Senate reached out to (Southurst, 2013). The DHS responded by immediately declaring cryptocurrencies as not only a threat, but also a way for criminal organizations to take advantage of the anonymity and ease of transferring money. The Federal Reserve also recognized the threat cryptocurrencies posed to society; however, they also acknowledged that this technology could be useful if there was a way to regulate the system. The SEC responded by identifying that ICOs and cryptocurrencies fell under their area of jurisdiction as they were considered securities. They decided to meet with the Bitcoin Foundation, an organization that assists in educating people about virtual currencies, in order to learn more about the legal, technological, and regulatory implications from a pro-cryptocurrency perspective. As discussed later on in this paper, this educational process, involving regulators and cryptocurrency experts, is ongoing and has helped to alleviate some of the uncertainty in the ICO space. However, further collaboration is required to optimize this relationship and to translate it into increased investor protection alongside efficient capital transfer channels for firms.

\section{Kin}

As a prominent ICO in recent times, involving an established company with industry expertise and a reputation for previously achieved rapid user base growth (EEA, 2017), a detailed analysis of the Kin ICO, initiated by the Canadian firm Kik Interactive, can enable a more wholesome discussion on ICO regulation by enabling the identification and interpretation of significant regulatory gaps that currently exist in the ICO space (Darko, 2017). Devised as a cross-platform solution to connect different mobile users, the Kik Messenger app from Kik Interactive was released in 2010 (Esch, 2010) and quickly accumulated a user base surpassing one million users (Perez, 2010). In September 2017, the company was able to successfully raise $168,732 \mathrm{ETH}$ from 10,000 investors as well as $\$ 50$ million from a pre-sale to institutional investors, in exchange for the newly created "Kin" cryptocurrency (Russell, 2017b). This initiative was successful, despite admissions from founder Ted Livingston himself that 
user growth of the Kik app, and in particular the number of active users, had stagnated and perhaps even experienced a decline from earlier peaks.

However, there are various factors which separate Kin from most other ICOs and can thereby potentially assist in explaining its comparative success. For example, as an established player in the online messaging space, Kik had previously secured funding from well-known firms such as Tencent. The company was working to integrate revenue generation strategies into its business model, by encouraging user interaction with brands (Russell, 2017a), leading to its ability to hold a successful presale of Kin tokens to institutional investors such as BlockChain Capital and PolyChain Capital, raising \$50 million (Shubber, 2017). In addition, Kik had an existing user base with members who had previously used a form of online value referred to as Kin Points in a similar capacity, and therefore could be expected to willingly and actively experiment with different uses of Kin, enabling network effects through the proliferation of the cryptocurrency. Furthermore, Kin outlined an interesting plan in its white paper to create an "ecosystem of everyday digital services" (Kik, 2017), suggesting planned longevity of the cryptocurrency and the potential for varied use.

Kik made the choice to disallow Canadian investors from participating in the ICO as the Ontario Securities Commission (OSC) had not provided clear guidance with regards to the applicable security laws that would need to be abided by to ensure investor protection, with Livingston preferring to classify the proposal as a "token distributions sale" as opposed to an ICO (De Vynck, 2017). However, it can be noted that Montrealbased social impact fintech firm Impak Finance was recently permitted to execute an ICO by the aforementioned OSC, raising over $\$ 1 \mathrm{M}$ in financial capital in what was advertised as the “America's 1st legal cryptocurrency crowdsale" (Impak, 2017). In this case, the key factor leading to this perceived policy divergence was Impak Finance's agreement to various conditions such as ongoing information, delivery to investors, know-your-client protections, anti-terrorism and anti-money laundering policies, and a maximum independent investor limit. Most importantly, Impak Finance agreed to regulator-imposed limits on secondary trading of the cryptocurrency (Goodmans, 2017).

Another potential consideration could be that as Impak Finance used the Waves platform, which was marketed as "fully transparent" (Impak, 2017), it would potentially be easier to audit and therefore earned favorable treatment from the OSC (FCAC, 2018). It can also be noted that there may have been justifiable concern about the possibility of scams associated with Kin. In fact, a fake URL circulated prior to the actual Kik ICO as a phishing scam resulted in 70.9 ETH being seized by a malicious party. According to third party observer Goodmans LLP, who analyzed the Canadian regulatory outcome, it appears that Kik's ICO was purposely structured to avoid compliance with Canadian securities regulation, seeking classification as a currency. Despite a failure to reach a satisfactory agreement with Canadian regulators, Kik was able to execute its pre-sale to American institutional investors by filing with the SEC and selling SAFT securities, aligned with an agreed-upon framework for investor protections, although retail investors were still locked out of the crowdsale (Kim, 2017). Even though Kik was a successful ICO, various detractors lamented that more regulation should be in place to protect investors who would, in essence, be involved in a highly speculative investment (Shubber, 2017), thereby validating the Canadian regulatory perspective to some extent.

\section{Benefits From ICO Market}

Returning to the underlying basis for regulatory intervention, an interesting aspect of ICOs to consider is that this method of funding allows companies to raise financial capital without the actual dilution of equity for existing shareholders. In addition, the crowdfunding nature of ICOs removes the involvement of intermediaries such as investment banks who normally underwrite security issuances, which thereby eliminates the hefty commissions associated with this process; however, it leaves the risk to be burdened by the cryptocurrency investors themselves. In addition, avoiding traditional investment structures may prevent ICO firms from having access to the same quality of investors, at least until the regulatory environment is stable enough to attract more institutional investors.

Currently, investors benefit from receiving new tokens from an ICO because the value of the coin can exponentially increase if the entity's initiative is successful, and therefore the returns justify the high risk. In addition, raising money without increasing debt is favorable for entities, particularly start-ups, because if the initiative fails, the entity will not be liable for outstanding debt that they would not be able to repay. Many start-up firms take a long time to become profitable because of the numerous initial financing costs that are incurred when the company begins operations. By issuing an ICO, firms can bypass third-party institutions and directly connect savers with investments.

\section{ICO: FAILURES AND SCAMS}

While there are many companies that have experienced financial success through crowdsales of altcoins, there are also people who see such a new trend as an opportunity to profit through fraudulent means. In fact, because ICO industry is still quite unregulated in most countries today, altcoin scams have become a commonly known phenomenon among cryptocurrency investors. In this section of the paper, two ICO businesses that have been identified by authorities as fraudulent will be analyzed, in order to understand the challenges presented to this emerging industry, as well as the possible regulatory means for it.

\section{REcoin}

REcoin, initiated in August 2017 by Maksim Zaslavskiy, was advertised as the "first ever cryptocurrency backed by real estate," as described by Zaslavskiy in a news release. It advertised that based on blockchain technologies, REcoin would be used as a means of payment replacing actual currencies in real estate transactions, which included real estate rentals using smart contracts at the time, and promised addition of sales contracts later. It was also promoted that "an international team of attorneys and programmers" was working on solutions for 
REcoin holders, as well as partnership with various "internet platforms" (REcoin, 2017). However, merely a month after the initial release of ICO, the SEC announced that it would prosecute Zaslavskiy for selling stock-like cryptocurrencies based on fraudulent claims. First of all, contradicting REcoin's initial announcement, it did not have any actual staff or operations within the business. Second, the business never invested the money gained from investors in crowdsales into the real estate market, hence, the SEC regarded it as a false presentation of investment value. Last and most importantly, REcoin did not run any blockchain of its own, meaning that the REcoin tokens practically did not exist (Morris, 2017).

In this case, the key takeaway for regulators and other observers would be the way this scam has occurred. On one hand, Zaslavskiy presented this fraudulent ICO project to investors with essentially minimal effort, which included only a white paper full of false claims and a social media marketing campaign. On the other hand, it became costly for investors to evaluate the true nature of this business as it required a certain level of expertise in blockchain and cryptocurrency, in addition to having the time to make investigations on the internet. Such a difference was created by information asymmetry, meaning that the amount of information provided in the white paper was not enough for investors to make decisions without either bearing high risks or incurring additional researching costs.

To investors, this specific case also raises questions about cryptocurrencies themselves. Most legitimate cryptocurrencies today are tied directly with certain cloud applications, in which they are used primarily as transaction media. REcoin proposed its tokens were backed by real estate, suggesting that if REcoin was real, it would link an online token with a real world offline asset using the blockchain technology. However, as commented by Fortune, "at least right now, there are few legal or technological means to link digital tokens to offline assets in the broader marketplace" (Morris, 2017). Investors should note that what could be processed over the internet using blockchain and smart contracts is still very limited to digital information, and any ICO projects claiming to be based on physical assets should be evaluated carefully.

\section{OneCoin}

Another fraudulent ICO is OneCoin, "a purported cryptocurrency and trading venture based out of Bulgaria" (Suberg, 2015). In comparison to REcoin, OneCoin is more organized, complicated, and difficult to investigate for individual investors. The business advertised itself as an educational organization, selling different packages with plagiarized contents to lure investors to mine OneCoin tokens that the business promised would quickly appreciate and split in quantities. However, while the supposed value of these tokens became higher, they are not in fact used in any applications besides to mine more tokens, and investors can hardly convert them to other currencies without significant commissions and quotas. Investors are only able to gain profit by assigning more new members into the organization, whose invested capital is used to pay the limited withdrawals of the old members on higher levels of this organization (Redman, 2016).
Due to the traits mentioned above, OneCoin has been widely identified by authorities and experts around the world as a Ponzi scheme, in which new members contribute their wealth to old members as revenue, without any actual economic value creation. In legitimate ICO projects, the increasing demand for cryptocurrencies usually come from the value they carry as a media for other applications on which entities make sales, purchases or transfers of funds. In the case of OneCoin, however, the supposedly increasing value of their tokens was derived entirely from the demand of new miners signed up. As such, while the detailed mechanics of Ponzi schemes are not relevant to this discussion, it is worth noting how the concept of cryptocurrencies can be used to cover such a scheme because again, individual investors are put in a disadvantageous position by their lack of sufficient knowledge, information, as well as a lack of resources to conduct their own investigations against an organized financial crime.

Meanwhile, within the discussion of ICO projects, what has been regarded by many as questionable, is the existence of the supposed "private" blockchain of OneCoin. The business claimed that it has its own blockchain from which OneCoin tokens could generate value. However, several traits of this "blockchain" showed in their promotion materials, as mentioned in the interview (Redman, 2016), counter what we would commonly expect from a legitimate blockchain. First of all, the fundamental ideology of blockchains is that they decentralize information, which would provide anonymity and security. OneCoin claimed to centralize transactions in their back office with a "private" blockchain, which is, even if technically possible, completely against incentives provided by the technology itself. Furthermore, OneCoin claimed that their tokens would appreciate in value with the increase in mining difficulties. It is common knowledge that without monetary policy intervention, the most critical factor that determines cryptocurrency value is its supply and demand, while mining difficulty is determined by adjustments based on block hashes. These logics indicate that, while OneCoin promoted itself as a cryptocurrency company, the cryptocurrency may only have been used as a smoke screen for the Ponzi scheme.

\section{Flaws of ICO Market}

After discussing the two companies that were both involved in promoting fraudulent ICO projects, we can identify some of the problems of the unregulated ICO industry. These problems are primarily derived from information asymmetry between ICO founders and investors, in terms of claims about the value of investment and legitimacy of blockchain.

The value of investments, or the projects described in white papers of ICOs, should be evaluated from two perspectives. First, as suggested by the REcoin case, it should be determined if documented business assets, either physical or intellectual, do really exist and can be utilized by the ICO project to create value. Such an evaluation would show that REcoin did not have sufficient assets, staffs or business relations to support its proposed operations. Second, as suggested by the OneCoin case, provided that the aforementioned assets do exist, further analysis should focus on whether or not the proposed business model outlined in the ICO white paper can efficiently use these assets 
to generate investment returns that are comparable with the project's claims. This analysis would logically discover that the proposed business model of OneCoin was not probable.

The legitimacy of the blockchain, on the other hand, would also be evaluated on two levels. First of all, a functional blockchain that can withstand independent audits has to exist for the ICO to be legitimate. In the case of OneCoin, if the organization is required to prove the existence of their "private blockchain" by either publishing at least part of their algorithm in the white paper, or inviting third-party involvement to audit their blockchain, it would have been much more difficult for the scheme to succeed. Even if the blockchain does exist, it still needs to be evaluated in terms of its functionality. For example, if REcoin did have a blockchain, what should be questioned is whether or not it can really integrate ownerships of offline physical assets, and furthermore, even if it could, it should be carefully analyzed whether or not such operations are within the protection of the legal system, especially when high-value properties like real estate are involved.

The evaluations mentioned above would theoretically benefit investors, as enforcing them should eliminate or at least diminish the information asymmetry within the industry. If investors welcome regulations that can reduce their risks in the cryptocurrency market (Ngo, 2017), an important consideration is if the implementation of these factors is truly probable, without undermining the fundamental values of cryptocurrencies and ICOs.

\section{THE REGULATION PARADOX}

\section{The Fundamental Conflict}

As a summary of the previous sections, it is now clear that ICOs of blockchain projects, that are similar to securities or not, if in fact decent, are at large beneficial to many stakeholders in economies, including investors, entrepreneurs, as well as users of services and products related to these projects. On the other hand, it is also revealed that if unchecked, fraudulent ICO projects that usually appear as Ponzi Schemes can cause great losses for investors, while requiring more than what common investors are often equipped with to be identified. It would seem that regulations should be imposed at least to a degree that eliminates those who rely on falsified information and prey on those who are disadvantageous in the created information asymmetry. However, it could be argued that any level of regulations imposed could in some degree constraint the benefits of ICOs.

One promising channel to regulate ICOs would be its supply. By requiring that all upcoming ICOs to be approved by the government first and centralizing the process of granting permissions to some certain agency such as the Ontario Securities Commission (OSC) in the Province of Ontario, Canada, the government would be able to assess the integrity of a project by evaluating the assets, talents as well as funds behind the project before releasing it to the market. This general class of methods could lead to a few problems. One is the bias in assessment, which we define as the regulating agency's subjective bias in regarding certain business models as portraying less decency than others. One example is in Canada, which is the first nation to legalize on the issue of cryptocurrencies (Duhaime, 2014). As the senate ruled the regulation responsibilities to the securities regulators and cryptocurrencies as "money service businesses" (MSB), it could be speculated that by categorizing a new market phenomenon as something familiar, the government understandably made the issue easier to handle, but at the same time risk the probability of handling a new distinctive entity using inappropriate standards. As the market develops, many new business models would also be created against conventional beliefs, which has been proven many times in history, such as businesses like Uber and Airbnb that have become an antithesis to the traditional assumption about the correlation between sustainability and ownership of core physical assets in their respective industries. As new blockchain-based business models are introduced, the regulatory agencies tuned in old practices could be reluctant in granting approvals, and a system that's supposed to protect investors would become detrimental to market innovations.

Another problem related to such regulatory structures, is the differentiated goals, which we define as the fact that world governments may not have the same objective when setting up such regulations, and hence would create different mandates for their regulatory bodies. For example, in many countries capital outflows are severely controlled, such as China, whether due to the economic theory of the "impossible trinity," which says a country cannot simultaneously have both free capital flows, controlled exchange rate, and sovereign monetary policy (Aizenman et al., 2013), or due to other more political concerns. For these countries, cryptocurrencies can be seen as a tool to anonymously and securely transfer capital out of the economy outside the sights of the state. Therefore, regulating cryptocurrencies through the requirement of approval from the government, would likely force startups to cooperate with the states in regulating their users' capital flows through restrictions and identifications, which is in principle against the initial objectives of blockchainanonymity and decentralization (without the interference of a centralized organization). Similarly, for different governments in the world, other mandates differentiated from simply guarding investors can all be enforced by the regulatory agencies, and often in some way undermining the benefits received by investors and businesses.

For other means of regulating ICOs, it is also possible to list the negative effects they would bring to stakeholders, but it is reasonable at this point to argue that such occurrences are unavoidable whichever means are chosen. It is because there exists the "regulation paradox," which we define as the fundamental conflict between regulation and the principle of decentralization. Regulation requires the centralization of information, asks that individuals (persons and business entities) to be segmented under categories (such as money service businesses a.k.a. "MSB") and boundaries (such as states), while decentralization in contrast, asks to replace the central structure with a trusted algorithm, and to eliminate segmentations, as individuals, rather than tagged groups, are represented by their own traits. Regulation protects individuals by decreasing risks, traded off with individuality, but decentralization enhances 
individuals by transferring power to individuality, but also at the cost of escalated risks. It is not in our context to compare these two terms on merits, but more importantly to note that it is very difficult, at least under the contemporary social structures, to find a perfect balance between them-to attain the optimal benefits of blockchain and cryptocurrencies while avoiding most risks in the market. It is possible that, whichever way the ICO market progresses in the future, regulators and market participants would both have to make trade-offs between the risks and benefits. However, it is possible to find means outside governments to reduce the risks of this market, as proposed by many ideologists, such as transforming the economy to a decentralized state, but this is not be a part of the discussion in this paper.

\section{Market Responses}

The market has responded to the fundamental conflicts discussed previously in many ways since the early stages of ICO. One significant trend is the separation between projects of pure blockchain application and those involving tokens. While the regulation paradox has caused much uncertainty in approaches different governments around the world take, countries have been quite in synchronization on their enthusiasm about the technological application. For instance, the financial technology (Fintech) sector has been eager to explore how blockchain could transform the financial infrastructures, improve their efficiencies and lower the costs. In fact, while still feeling constrained by regulatory uncertainties, Canadian banks have been experimenting with blockchain technology for some period (Willms, 2016).

More recently in 2018, as the market has witnessed the large fluctuations in cryptocurrency prices, resulted from the high risks of smaller-scale tokens that had been flushing into the market, a new trend of stable cryptocurrency, or in short "stablecoin," has started to take over. As the name suggests, stablecoin is essentially cryptocurrencies without the price volatility, as stablecoins are often portrayed as being pegged to some certain legal currencies, such as the US dollar. While some are optimistic that this new type of cryptocurrency would be the savior of this seeming trembling sector, others have been critical about this product. The reason behind such critical views reside in how stablecoins are created, and there are three primary forms.

First, stablecoins can use fiat money as a collateral, which means investors could deposit some amount of US dollar into the account of a central organization, often a third-party bank, and then receive a quantity of stablecoins equivalent to the deposit. The value of the stablecoins would not fluctuate according to market conditions but are firmly pegged to the fiat currency, and hence guarantees that investors can hedge against risks in the cryptocurrency market. The major problem with this form of stablecoins is that it requires some central organization to process all transactions, which is against the principle of decentralization. Meanwhile, since the first money used as collaterals cannot be reinvested by the collateral holders, it would cause significant wastes of capital. The second form of stable coin uses cryptocurrency as the collateral, meaning that investors would deposit some amount of cryptocurrency assets into a smart-contract account to receive some quantity of stable coins. However, due to the fact that cryptocurrencies are volatile, this type of stablecoins is often "overcollateralized," which means the ratio between received stablecoin to the deposited cryptocollateral can be incredibly low. The third form of stablecoins, is the non-collateralized stablecoins. These stablecoins would remain in the long term a stable value as their algorithms are designed to adjust the supply based on the price, according to theories in monetary economics. However, it should be noted that limits on how much adjustments on supply can affect the token value exist, and the coin is not completely immune to market conditions (Allen, 2018).

Apart from the fact that the market is still unsure if the latter two forms of stablecoins would be functional and sustainable in the long run, before they can actually help cryptocurrencies to dominate the market (Orcutt, 2018), this case shows that even when the market responses by seeking to decrease risks, investors still have to make trade-offs between risks and, whether the efficiency of capital, the safety brought by collaterals, or the basic value of being decentralized. At the same time, the trend of stablecoins also shows that even though a paradox does exist in government regulation, conflicting with decentralization, technological or methodological innovations could still occur outside of governments to gradually transform the market.

\section{Policy Responses}

Governments around the world have also responded to the expanding cryptocurrency market in different ways, each attempting to avoid the regulation paradox with approaches two different ends of the political spectrum. On the one end locates Canada, which as discussed in earlier sections, regulates by assessing ICOs case by case and grant approvals to them. The Canadian Senate in fact proposed that "... blockchain technology is at a delicate stage in its development and use... This is why we urge the Government to explore the vast potential of this technology, while treading carefully when contemplating regulations that may restrict and stifle its use and development." (Willms, 2015) The statement well summarizes the attitude of Canadian government on cryptocurrencies, as they later granted regulatory exemptions to blockchain businesses in order to incentivize entrepreneurs to invest into innovations in the field of blockchain technology (Jackson, 2018). While the regulation paradox still holds, the Canadian government is willing to open the market and watch closely to frequently adjust regulations in a very flexible and dynamic approach, which could be beneficial for start-up companies that are willing to experiment with the Canadian government.

Another country, in contrast, is China, which has famously or infamously banned ICOs since it realized the threats of inflating tokens, fraudulent funding schemes and possible market bubbles, while without the appropriate regulatory tools to solve the problem $(\mathrm{Li}, 2017)$. However, China has not given up on blockchain research. Since the restrictive regulations on cryptocurrencies are issued, provincial and municipal governments in China have been setting up their own research facilities such as the Hangzhou Blockchain Industrial Park, in the City of Hangzhou, Province of Zhejiang, China, with 
capitals from both governments and capitalists. This approach chosen by the Chinese government is to solely focus on pure blockchain applications, while waiting for other governments to experiment with the token regulations first (Makadiya, 2018). It's an understandable choice following China's demographics in comparison to Canada, as its huge population and averagely undereducated investors could escalate the consequences of fraudulent ICO projects or market fluctuations much faster and much more uncontrollably.

From these two examples, we can tell that major blockchaininvolved nations around the globe are still in the period of exploring how this newly emerged technology, as well as all the products derived from it could be properly handled by individuals, the market, and the states. As the market matures in an indefinite time, the regulation paradox could become more severe in an expanded global cryptocurrency economy, therefore forcing countries to make an ultimate choice between embracement or rejection. Or, as we would hope to see, new developments in both technologies and social structures would allow the paradox to diminish in a new age.

\section{CONCLUSION}

As an increasingly popular, yet sub-optimally regulated and controversial form of capital generation and value exchange, the use of cryptocurrencies and ICOs has brought society significant advantages including anonymity, security, and capitalization convenience. Taking a retrospective perspective with regards to the earlier discussion, two companies were analyzed in terms of how the ICOs market has impacted both businesses and investors, with a generally more favorable outcome for issuing firms. Mastercoin was the first ICO, creating the concept of digital token crowdsales with the expectation of value appreciation. Its existence unveiled the massive investment demand for different cryptocurrencies. Kik was able to execute a somewhat successful Kin ICO, relying heavily on its existing reputation as a successful online messaging provider when it launched its ICO, which greatly improved its performance in the investment market. From these cases, it can be argued that ICOs provide start-ups with an opportunity to raise money without increasing either debt or equity, and bypassing third-party institutions.

However, fraudulent companies such as REcoin and OneCoin have also come to prey on investors in this market. REcoin's

\section{REFERENCES}

Aizenman, J., Chinn, M., and Ito, H. (2013). The "Impossible Trinity" hypothesis in an era of global imbalances: measurement and testing. Rev. Int. Econ. 21, 447-458. doi: 10.1111/roie.12047

Allen, T. (2018). The Rise of Stablecoins. Coin Journal. Retrieved from https:// coinjournal.net/the-rise- of-stablecoins/ (accessed September 29, 2018).

BlockGeeks (2016). What is Blockchain Technology? A Step-by-Step Guide for Beginners. BlockGeeks. Retrieved from https://blockgeeks.com/guides/what-isblockchain-technology/ (accessed November 12, 2017).

Boggavaram, P. (2017). Cryptocurrency Valuation: What Are the Main Drivers? The Market Mogul. Retrieved from https://themarketmogul.com/ cryptocurrency-valuation-drivers/ (accessed November 12, 2017).
Maksim Zaslavskiy blatantly lied about the nature of his business' existence, but many investors did not have enough knowledge about cryptocurrencies or resources to investigate if the information being presented was accurate. Due to this lack of regulatory oversight, all it took was a simple marketing campaign and false white paper claims to engineer a scam which essentially robbed investors of their money. Organizations like OneCoin, on the other hand, prove that traditional financial crime models such as Ponzi schemes could be reintroduced under the guise of ICOs, and it would be even more difficult for investors to discover the true nature of such entities individually. In summary, information asymmetry is a key disadvantage to investors hoping to invest in ICOs. Therefore, evaluations of ICO projects should be carried out to minimize the risks of investors through elimination of such asymmetry, and synchronized regulatory oversight appears to be the ideal outcome to facilitate a fairer transaction process.

In short, this paper aimed to examine certain cases in this industry to show that ICOs have revolutionized the way businesses and consumers think, while also facing controversy due to a lack of efficient regulatory structures. However, it has been pointed out that implementing some regulations may defeat the original purpose of ICOs, and as this industry expands, key players from both sides of the debate will have to compromise to choose the appropriate balance between the risks and benefits brought by it. The fundamental conflict between regulation and decentralization seems to be unavoidable, and the regulation paradox will continue to exist in the industry without technological and social breakthroughs. Clearly, every proposed initiative to strengthen investor relations seems to have a possible step forward as well as a step backward for both parties. Overall, the potential for ICOs to become a prominent part of the economy does exist, but only time will tell just how successfully this form of financing will be adopted on a global scale, and whether or not it will ultimately emerge as a dominant financing mechanism, surpassing both equity and debt financing.

\section{AUTHOR CONTRIBUTIONS}

Each author contributed to the writing and research of this paper. The ordering of the authors signifies the relative contribution of each author, though each author contributed significantly. 
Duhaime, C. (2014). Canada Implements World's First National Digital Currency Law; Regulates New Financial Technology Transactions. Duhaime Law. Retrieved from https://www.duhaimelaw.com/ 2014/06/22/canada-implements-worlds-first-national-bitcoin-law/ (accessed September 29, 2018).

EEA (2017). Enterprise Ethereum Alliance expands dramatically announcing 86 new members including Broadridge, DTCC, Deloitte, Infosys, Merck KGaA, MUFG, National Bank of Canada, Rabobank, Samsung SDS, State Street, Toyota and many of the most innovative startups in the Ethereum Ecosystem. Enterprise Ethereum Alliance. Retrieved from https://entethalliance.org/ enterprise-ethereum-alliance-release-05-19-2017.pdf (accessed November 5, 2017).

Esch, J. (2010). Kik Messenger Gets off to a Good Start After October Relaunch. Third Age. Retrieved from https://web.archive.org/web/ 20110721121837/http://www.thirdage.com/news/kik-messenger-getsgood-start-after-october-relaunch_11-4-2010 (accessed November 5, 2017).

FCAC (2018) Digital Currency. Financial Consumer Agency of Canada, Government of Canada. Retrieved from https://www.canada.ca/en/ financial-consumer-agency/services/payment/digital-currency.html (accessed November 5, 2017).

Goodmans (2017). Cryptocurrencies: Further Legal Developments. Goodmans LLP. Retrieved from http://www.goodmans.ca/files/file/docs/09.12.2017 \%20Securities\%20and\%20Technology\%20Update.pdf (accessed November 5, 2017).

Guttmann, B. (2014). The Bitcoin Bible Gold Edition: All You Need to Know About Bitcoins and More. Norderstedt: Books on Demand.

Impak (2017). Canada’s 1st Legal Cryptocurrency Crowdsale Launched by Dimpak Finance. Newswire. Retrieved from http://www.newswire.ca/news-releases/ canadas-1st-legal-cryptocurrency-crowdsale-launched-by-impak-finance640700373.html (accessed November 5, 2017).

Investopedia. (2018). Initial Coin Offering. Investopedia. Retrieved from https://www.investopedia.com/terms/i/initial-coin-offering-ico.asp (accessed November 11, 2017)

Jackson, D. (2018). How Canada Has Become a Leading Blockchain Nation. Stockhouse. Retrieved from http://www.stockhouse.com/news/ newswire/2018/08/15/how-canada-has-become-leading-blockchain-nation\# 5HqsKJldrqRbQMM7.99 (accessed September 29, 2018).

Kik (2017). Kin: A Decentralized Ecosystem of Digital Services for Daily Life. Kik Interactive. Retrieved from https://kin.kik.com/papers/Kin_Whitepaper_V1_ English.pdf (accessed November 5, 2017).

Kim, E. (2017). Crypto start-ups are trying to get their house in order ahead of a possible SEC crackdown. CNBC. Retrieved from https://www.cnbc.com/2017/ 10/12/crypto-start-ups-turn-to-safts-for-icos-raising-more-than-350m.html (accessed November 5, 2017).

Li, C. (2017). China Bitcoin Exchange to Stop Trading Virtual Currencies Amid Crackdown. The New York Times. Available online at: https://www.nytimes. com/2017/09/14/business/china-bitcoin-exchange.html (accessed September 14, 2017).

Makadiya, A. (2018). China’s Hangzhou Blockchain Industrial Park Opens With \$1.6 Billion Backing. Bits Online. Retrieved from https:// bitsonline.com/hangzhou-blockchain-industrial-park/ (accessed September 29, 2018).

Morris, D. (2017). The SEC Filed Fraud Charges against 2 'Initial Coin Offerings'. Fortune. Retrieved from http://fortune.com/2017/10/01/sec-icofraud-charges/ (accessed November 6, 2017).

Ngo, D. (2017). Survey: Malaysians Warm Up to Cryptocurrencies, Bitcoin Still on Top. NASDAQ. Retrieved from http://www.nasdaq.com/article/surveymalaysians-warm-up-to-cryptocurrencies-bitcoin-still-on-top-cm798146 (accessed November 6, 2017).

Orcutt, M. (2018). Stablecoins will help cryptocurrencies achieve world domination-if they actually work. MIT Technology Review. Retrieved from https://www.technologyreview.com/s/612207/stablecoins-will-helpcryptocurrencies-achieve-world-dominationif-they-actually-work/ (accessed September 29, 2018).
Perez, M. (2010). Kik Messenger App Blows past 1 Million Users. Into Mobile. Retrieved from http://www.intomobile.com/2010/11/05/kik-messenger-appiphone-blackberry-android/ (accessed November 5, 2017).

REcoin (2017). REcoin: The First Ever Cryptocurrency Backed by Real Estate, Confirms Token Pre-Sale and ICO Launch Dates. Newswire. Retrieved from https://www.prnewswire.com/news-releases/recoin-the-first-evercryptocurrency-backed-by-real-estate-confirms-token-pre-sale- and-icolaunch-dates-300487074.html (accessed November 6, 2017).

Redman, J. (2016). Buyer Beware! The Definitive OneCoin Ponzi Exposé. Bitcoin.com. Retrieved from https://news.bitcoin.com/beware-definitiveonecoin-ponzi/ (accessed November 6, 2017).

Reuters (2017). Cryptocurrency Chaos as China Cracks Down on Initial Coin Offerings. Fortune. Retrieved from http://fortune.com/2017/09/12/ cryptocurrency-china-initial-coin-offerings/ (accessed November 11, 2017).

Russell, J. (2017a). Kik Introduces Promoted Chats to Let Brands on Its Messaging App and Finally Make Money. Tech Crunch. Retrieved from https:// techcrunch.com/2014/11/06/kik-introduces-promoted-chats-to-let-brandson-its-messaging-app-and-finally-make-money/ (accessed November 5, 2017).

Russell, J. (2017b). Kik Raises Nearly $\$ 100 \mathrm{M}$ in Highest Profile ICO to Date. Tech Crunch. Retrieved from https://techcrunch.com/2017/09/26/kik-ico-100million/ (accessed November 5, 2017).

Shin, L. (2017). Here's the Man Who Created ICOs and This Is the New Token He's Backing. Forbes. Retrieved from https://www.forbes.com/sites/laurashin/ 2017/09/21/heres-the-man-who-created-icos-and-this-is-the-new-tokenhes-backing/ (accessed November 3, 2017).

Shubber, K. (2017). Crypto-bailouts for struggling startups. Financial Times. Retrieved from https://ftalphaville.ft.com/2017/08/30/2193002/cryptobailouts-for-struggling-startups/ (accessed November 5, 2017).

Southurst, J. (2013). Federal Agency Responses Reveal US Government Attitudes to Bitcoin. Coindesk. Retrieved from https://www.coindesk.com/federalagency-responses-us-government-attitudes-bitcoin/ (accessed November 3, 2017).

Suberg, W. (2015). One Coin, Much Scam: OneCoin Exposed as Global MLM Ponzi Scheme. Coin Telegraph. Retrieved from https://cointelegraph.com/ news/one-coin-much-scam-onecoin-exposed-as-global-mlm-ponzi-scheme (accessed November 6, 2017).

Swan, M. (2015). Blockchain: Blueprint for a New Economy. Sebastopol, CA: O’Reilly Media.

Willms, J. (2015). Canadian Senate Says No to Regulating Digital Currencies. Bitcoin Magazine. Retrieved from https://bitcoinmagazine.com/articles/ canadian-senate-says-no-regulating-digital-currencies-1434759556/ (accessed September 29, 2018).

Willms, J. (2016). Canadian Banks Experiment with Blockchain Technology; Fintech Sector Calls for Regulatory Certainty. Bitcoin Magazine. Retrieved from https://bitcoinmagazine.com/articles/canadian-banks-experimentwith-blockchain-technology-fintech-sector-calls-for-regulatory-certainty1469731299/ (accessed September 29, 2018).

Wilmoth, J. (2014). What is an Altcoin? Crypto Coins News. Retrieved from https:// www.cryptocoinsnews.com/altcoin/ (accessed November 11, 2017).

Yadav, M. (2017). Exploring Signals for Investing in an Initial Coin Offering (ICO). Available online at SSRN: https://ssrn.com/abstract=3037106 (accessed October, 2018).

Conflict of Interest Statement: The authors declare that the research was conducted in the absence of any commercial or financial relationships that could be construed as a potential conflict of interest.

Copyright $\odot 2019$ Zhang, Raveenthiran, Mukai, Naeem, Dhuna, Parveen and Kim. This is an open-access article distributed under the terms of the Creative Commons Attribution License (CC BY). The use, distribution or reproduction in other forums is permitted, provided the original author(s) and the copyright owner(s) are credited and that the original publication in this journal is cited, in accordance with accepted academic practice. No use, distribution or reproduction is permitted which does not comply with these terms. 